\title{
Gluing Langmuir-Blodgett Monolayers Onto Hydrocarbon Surfaces
}

\author{
Junwei Li, Vaclav Janout and Steven L. Regen* \\ Department of Chemistry, Lehigh University, Bethlehem, Pennsylvania 18015
}

\section{Supporting Information}

Materials. Poly(sodium 4-styrenesulfonate) $(\mathrm{Mw}=70,000)(\mathrm{PSS})$ and poly(maleic anhydride-alt-1-octadecene) $(\mathrm{Mw}=30,000-50,000)$ were purchased from Polysciences Inc.; $n$-dioctadecyldimethylammonium bromide was obtained from Eastman Kodak. Poly(diallydimethylammonium chloride) (PDADMA) $(\mathrm{Mw}=100,000-200,000)$ and $n$ octadecyltrichlorosilane (OTS) were purchased from Aldrich. Calix[6]arene 1a was synthesized using methods previously described. ${ }^{1}$ 27,28,29,30-Tetra- $n$-hexadecyloxycalix[4]arene (cone conformer) was synthesized using procedures similar to those described in the literature, except that DMF was used in place of THF. ${ }^{2}$. Housedeionized water was purified using a Millipore Milli-Q-filtering system containing one carbon and two ion-exchange stages. A Nima 612D film balance (Nima Technologies, Coventry England) was used for all monolayer experiments.

\section{5,11,17,23-Tetraformyl-27,28,29,30-tetra-n-hexadecyloxy-calix[4]arene (cone} conformer). To a stirred solution made from $4.74 \mathrm{~g}$ of $\mathrm{TiCl}_{4}(25 \mathrm{mmol})$ and $5.75 \mathrm{~g} \mathrm{1,1-}$ dichloromethyl methyl ether $(50 \mathrm{mmol})$ was added, dropwise, a solution that was made from $2.9 \mathrm{~mL}$ of $\mathrm{CHCl}_{3}$ and $0.349 \mathrm{~g}(0.265 \mathrm{mmol})$ of 27,28,29,30-tetra- $n$-hexadecyloxycalix[4] arene (cone conformer) at $40^{\circ} \mathrm{C}$ under and argon atmosphere. After stirring for 1 $\mathrm{h}$, the mixture was diluted with $40 \mathrm{~mL}$ of $\mathrm{CHCl}_{3}$ and poured onto $100 \mathrm{~g}$ of ice. The crude product was extracted with an additional $100 \mathrm{~mL}$ of $\mathrm{CHCl}_{3}$ and the combined organic layer washed with water $(5 \times 30 \mathrm{~mL})$ and dried over anhydrous $\mathrm{Na}_{2} \mathrm{SO}_{4}$. The solution was then concentrated under reduced pressure and the residue purified by preparative thin layer chromatography $\left[\mathrm{SiO}_{2}, \mathrm{CHCl}_{3} / \mathrm{EtOH}, 10 / 1(\mathrm{v} / \mathrm{v})\right]$ to give $0.211 \mathrm{~g}(55 \%)$ of the title 
compound having ${ }^{1} \mathrm{H}$ NMR (360MHz, $\left.\mathrm{CDCl}_{3}\right)$ : 9.56(s, 4H); 7.13(s, 8H); 4.46(d, 4H); 3.93(t, $8 \mathrm{H}) ; 3.32(\mathrm{~d}, 4 \mathrm{H}) ; 1.85(\mathrm{~m}, 8 \mathrm{H}) ; 1.23(\mathrm{~m}, 104 \mathrm{H}) ; 0.85(\mathrm{t}, 12 \mathrm{H})$.

\section{5,11,17,23-Tetrakis(hydroxymethyl]-27,28,29,30-tetra-n-hexadecyloxy-calix[4]arene} (cone conformer). To a stirred solution of $200 \mathrm{mg}(0.139 \mathrm{mmol})$ of 5,11,17,23tetraformyl-27,28,29,30-tetra- $n$-hexadecyloxy-calix[4] arene (cone conformer) in $2.1 \mathrm{~mL}$ of anhydrous tetrahydrofuran was added $0.62 \mathrm{~mL}$ of a $1 \mathrm{M} \mathrm{THF}$ solution of $\mathrm{LiAlH}_{4}$. The resulting mixture was stirred at room temperature under an argon atmosphere for $2 \mathrm{~h}$ and than quenched by adding, sequentially, $2 \mathrm{~mL}$ of $\mathrm{H}_{2} \mathrm{O}$ and $10 \mathrm{~mL}$ of $0.2 \mathrm{M} \mathrm{HCl}$. The crude product was extracted with $\mathrm{CHCl}_{3}(2 \times 20 \mathrm{~mL})$, washed with water $(5 \times 30 \mathrm{~mL})$ and dried over anhydous $\mathrm{Na}_{2} \mathrm{SO}_{4}$. After being concentrated under reduced pressure, the residue was purified by preparative thin layer chromatography $\left[\mathrm{SiO}_{2}, \mathrm{CHCl}_{3} / \mathrm{MeOH}\right.$, $10 / 1 /(\mathrm{v} / \mathrm{v})]$ to give $152 \mathrm{mg}(76 \%)$ of the title compound having $\mathrm{R}_{\mathrm{f}} 0.46$ and ${ }^{1} \mathrm{H} \mathrm{NMR}$ $\left(360 \mathrm{MHz}, \mathrm{CDCl}_{3}\right): 6.65(\mathrm{~s}, 8 \mathrm{H}) ; 4.40(\mathrm{~d}, 4 \mathrm{H}) ; 4.32(\mathrm{~s}, 8 \mathrm{H}) ; 3.84(\mathrm{t}, 8 \mathrm{H}) ; 3.12(\mathrm{~d}, 4 \mathrm{H})$; 2.69(bs, 4H); 1.89(m, 8H); 1.24(m, 104H); 0.87(t, 12H).

\section{5,11,17,23-Tetrakis(chloromethyl)-27,28,29,30-tetra- $n$-hexadecyloxy-calix[4]arene,} (cone conformer). A solution that was prepared from $72.0 \mathrm{mg}(53.7 \mu \mathrm{mol})$ of 5,11,17,23-tetrakis(hydroxymethyl]-27,28,29,30-tetra- $n$-hexadecyloxy-calix[4]arene, (cone conformer), $840 \mu \mathrm{L}$ of chloroform and $60 \mu \mathrm{L}$ of $\mathrm{SOCl}_{2}$ was stirred at room temperature for $1.5 \mathrm{~h}$. The product mixture was then diluted with $9 \mathrm{~mL}$ of $\mathrm{CHCl}_{3}$ and washed three times with $9 \mathrm{~mL}$ of water. The organic phase was concentrated under reduced pressure to a volume of $0.5 \mathrm{~mL}$ and the crude product then purified by preparative thin layer chromatography $\left(\mathrm{SiO}_{2}\right.$, hexanes/ethylacetate,16/1, v/v) to give 21 $\mathrm{mg}(26 \%)$ of 5,11,17,23-tetrakis(chloromethy)-27,28,29,30-tetra- $n$-hexadecyloxycalix[4] arene having ${ }^{1} \mathrm{H}$ NMR $\left(360 \mathrm{MHz}, \mathrm{CDCl}_{3}\right): 6.64(\mathrm{~s}, 8 \mathrm{H}) ; 4.40(\mathrm{~d}, 4 \mathrm{H}) ; 3.87(\mathrm{t}, 8 \mathrm{H})$; 3.11(d, 4H); 1.86(m, 8H); 1.26(m, 104H); 0.87(t, 12H).

\section{5,11,17,23-Tetrakis (N,N,N-trimethylammonium-N-methyl]-27,28,29,30-tetrakis- $n$ - hexadecyloxy-calix[4]arene, hexachloride (cone conformer) (1b). To a solution of} $65.0 \mathrm{mg}(42.7 \mu \mathrm{mol})$ of 5,11,17,23-tetrakis(chloromethyl]-27,28,29,30-tetra- $n$ - 
hexadecyloxy-calix[4]arene, (cone conformer) in $3.0 \mathrm{~mL}$ of 1,4-dioxane was added 3.0 $\mathrm{mL}$ of a $31 \%$ ethanolic solution of trimethylamine $(12.4 \mathrm{mmol})$. The mixture was then stirred at $40^{\circ} \mathrm{C}$ in a sealed flask for $2 \mathrm{~h}$, cooled to room temperature and diluted with 10 $\mathrm{mL}$ of hexanes. The resulting solid was removed by filtration and recrystallized from chloroform/hexanes, $1 / 1(\mathrm{v} / \mathrm{v})$ to give $41.2 \mathrm{mg}(51 \%)$ of $\mathbf{1 b}$ as white needles having ${ }^{1} \mathrm{H}$ NMR (360 MHz, $\left.\mathrm{CDCl}_{3} / \mathrm{CD}_{3} \mathrm{OD}, 20 / 1, \mathrm{v} / \mathrm{v}\right)$ : 7.41 (s, 8H); 4.92(s, 8H); 4.57(d, 4H); $3.65(\mathrm{t}, 8 \mathrm{H}) ; 3.56(\mathrm{~d}, 8 \mathrm{H}) ; 3.06(\mathrm{~s}, 36 \mathrm{H}) ; 1.71(\mathrm{~m}, 8 \mathrm{H}) ; 1.26(\mathrm{~m}, 104 \mathrm{H}) ; 0.87(\mathrm{t}, 12 \mathrm{H})$. ESI $\mathrm{MS} m / z\left(\mathrm{M}^{4+}\right) 402.6$.

Substrate preparation. The silicon wafers that were used in this work was obtained from WaferNet, Inc. (San Jose, CA). These wafers were cut into $15 \times 25 \mathrm{~mm}$ pieces and were treated in concentrated $\mathrm{H}_{2} \mathrm{SO}_{4}$ and $30 \% \mathrm{H}_{2} \mathrm{O}_{2}\left(70 / 30\right.$, v/v) at $70^{\circ} \mathrm{C}$ for $4 \mathrm{~h}$. The wafers were then rinsed with distilled water, and dried under a stream of nitrogen, before being immersed in a $10 \mathrm{mM}$ anhydrous hexane solution of OTS for 30 minutes at room temperature. The wafers were then rinsed with hexane and chloroform. Poly(ethylene terephthalate) films (MELINEX, DuPont Teijin Films, Hopewell, Va) were used as obtained.

Monolayer Formation and Langmuir-Blodgett Transfers. Typically, $50 \mu \mathrm{L}$ of a surfactant solution ( $1 \mathrm{mg} / \mathrm{mL}$ of chloroform) was spread onto a pure water subphase (or a subphase containing a $5 \mathrm{mM}$ repeat unit concentration of PSS), which was maintained at $25^{\circ} \mathrm{C}$. After allowing the solvent to evaporate for $30 \mathrm{~min}$, the film was compressed at a speed of $25 \mathrm{~cm}^{2} / \mathrm{min}$ to a surface pressure of $30 \mathrm{dyn} / \mathrm{cm}$. The monolayer was then transferred to the hydrophobic substrate (OTS-modiefied silicon wafer or poly(ethylene terephthalate) by a single down-trip, maintaining the surface pressure at $30 \mathrm{dyn} / \mathrm{cm}$. The dipping speed that was used was $2 \mathrm{~mm} / \mathrm{min}$. After allowing the substrate to remain in the subphase for $60 \mathrm{~min}$, the compressing barrier of film balance was expanded to a maximum area, which reduced the surface pressure of film on the water surface to 0 
$\mathrm{dyn} / \mathrm{cm}$. The substrate was then pulled out of subphase (vertical up-trip) using speed of $50 \mathrm{~mm} / \mathrm{min}$. The monolayer was then compressed again and the isotherm recorded.

The substrate was then allowed to dry in air, and then washed in pure water by immersing it in a bath containing $125 \mathrm{~mL}$ of pure water for $10 \mathrm{~min}$, followed by removal and drying in air. This washing procedure was repeated two additional times. Finally, the substrate was dried in air for $24 \mathrm{~h}$ before further characterizations. It should be noted that samples transferred from pure water subphase on OTS treated silicon were characterized both before and after washing with water.

Layer-by-layer deposition of PDADMA and PSS. A glued monolayer of 1a/PSS that had been desposited onto an OTS-modified silicon wafer, and washed with water, was subjected to layer-by-layer deposition. Typically, the substrate was immersed, directly, into $125 \mathrm{~mL}$ of an aqueous solution of poly(diallyldimethylammonium chloride) (PDADMA, $5 \mathrm{mM}$ repeat unit) for $5 \mathrm{~min}$. The substrate was then removed and washed by immersing in $125 \mathrm{~mL}$ of pure water for $10 \mathrm{~min}$, followed by air-drying. This washing and drying cycle was then repeated once. A similar treatment was then performed using an aqueous solution of poly(styrene sulfonate) (PSS, $5 \mathrm{mM}$ repeat unit concentration).

Water Contact Angle and Ellipsometric Measurements. Water contact angles were measured using a Rame-Hart NRL model 100 goniometer. A minimum of six measurements were made for three independent drops that were placed at different locations along the substrate. Ellipsometric measurements were made using an automatic null ellipsometer (Rudolph Auto-EL III), equipped with a helium-neon laser $(\lambda=632.8$ $\mathrm{nm})$ that was set at an incident angle of $70^{\circ}$. Measurements were taken at four spots on the surface of each sample and the mean and the standard deviations were calculated. Film thickness was determined using the manufacturer's program, assuming a refractive index for OTS and the LB monolayer of 1.41. 
Atomic Force Microscopy (AFM) measurements. All AFM measurements were made using a tapping mode atomic force microscopy (Nano III, Multimode SPM, Veeco, Santa Barbara, CA). A minimum of three different locations along the surface was examined. For each location 1, 2 and $5 \mu \mathrm{m}$-size images were measured.

X-ray Photoelectron Spectroscopy (XPS) Measurements. Composition and depth profiles were measured using a Scienta ESCA-300 spectrometer (Scienta Instruments AB, Uppsala, Sweden). Angle resolved XPS measurements were performed at take-off angle of $11.5,23.6,36.9$ and $53.1^{\circ}$, respectively. The XPS analysis focused on the atomic composition for $\mathrm{N}, \mathrm{C}$, and $\mathrm{S}$ within the monolayer as a function of take-off angle.

Surface Viscosity Measurements. For surface viscosity experiments, a home-built canal viscometer $(192 \mathrm{~mm} \times 40 \mathrm{~mm}$ solid Teflon block, having a centrally located 6.0 $\mathrm{mm}$ slit) was placed in front of the compressing barrier and the monolayer was compressed to a surface pressure of $20 \mathrm{dyn} / \mathrm{cm}$. After the resulting monolayer was allowed to equilibrate at this pressure for 0,30 or $120 \mathrm{~min}$, the film was decompressed using a maximum speed of $120 \mathrm{~cm}^{2} / \mathrm{min}$, leaving the canal viscometer at its original position. The resulting surface pressure was then recorded as a function of time. The rate of surface pressure decrease was used as a measure of the surface viscosity of the monolayer. 

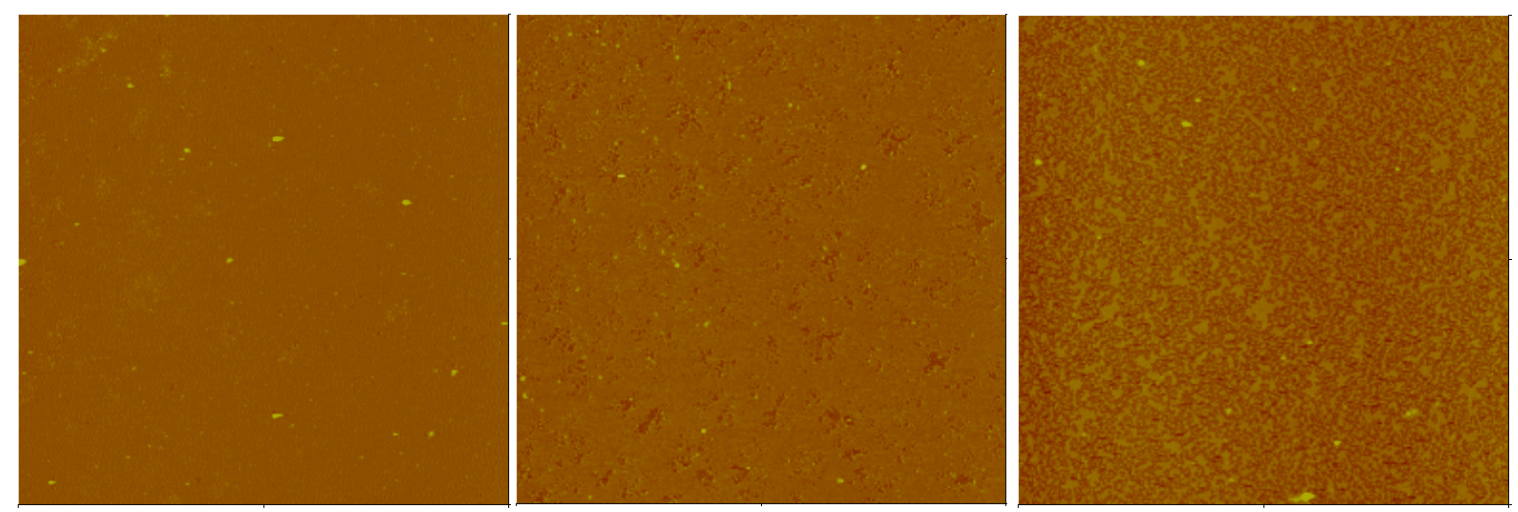

Figure $\boldsymbol{S}$-1. Height images (AFM, tapping mode, $5 \times 5 \mu \mathrm{m}$ ) of a deposited monolayer of 1a on an OTS-modified silicon wafer using: (Left) an aqueous subphase containing 5 mM PSS; (Middle) same as left, except that the monolayer was held for 60 min at 30 dyn/cm prior to transfer; (Right) a pure water subphase was used. All transfers were made using a speed of $2 \mathrm{~mm} / \mathrm{min}$ at constant surface pressure of $30 \mathrm{dyn} / \mathrm{cm}$. Monolayers that were deposited from a PSS subphase were washed with water (three times, 10 min each); the monolayer that was deposited from a pure water subphase was examined without rinsing.

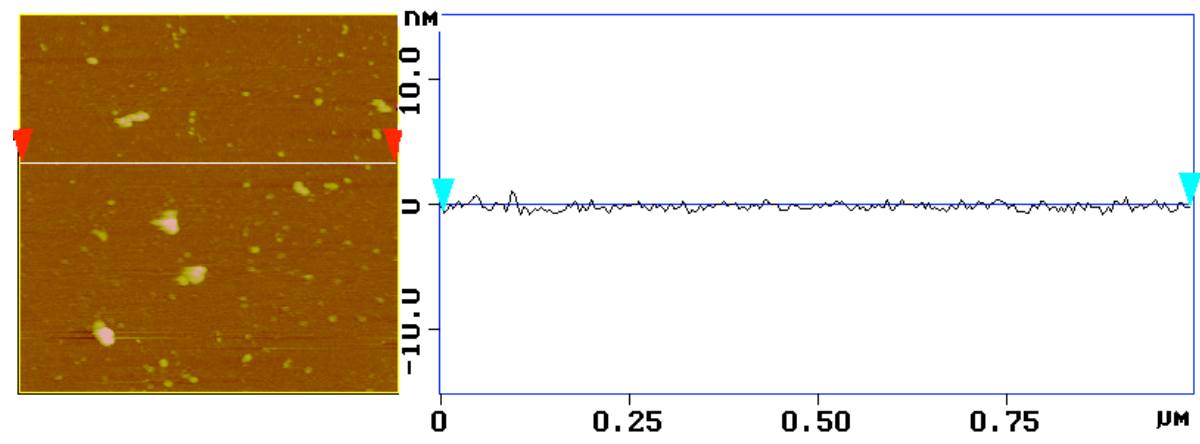

Figure $\boldsymbol{S}$-2. Height images (AFM, tapping mode, $1 \times 1 \mu \mathrm{m}$ ) and its section profile of a deposited, non-glued monolayer of $1 \mathbf{a}$ after washing in water (three times, $10 \mathrm{~min}$ each). In this case, the monolayer was transferred from a pure water subphase. 


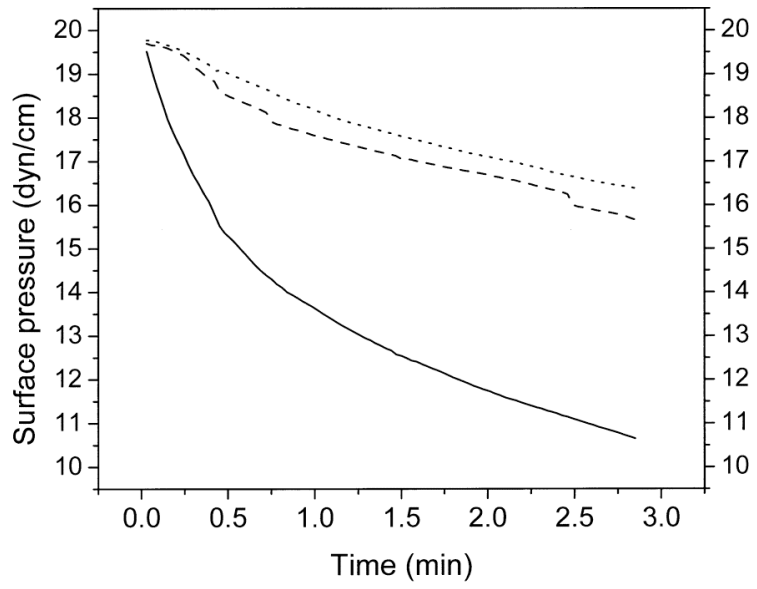

Figure $\boldsymbol{S}$-3. Surface pressure of a compressed monolayer of 1a over a PSS subphase as a function of time, after being exposed to a canal viscometer having a centrally-located 6.0 $\mathrm{mm}$ slit. The rate of surface pressure decrease was taken as a measure of the surface viscosity of the monolayer. The amount of time that the monolayer was held at 20 $\mathrm{dyn} / \mathrm{cm}$ prior to exposure to the slit opening was $0 \mathrm{~min}$ (solid line), $30 \mathrm{~min}$ (dotted line) and 120 min (dashed line).

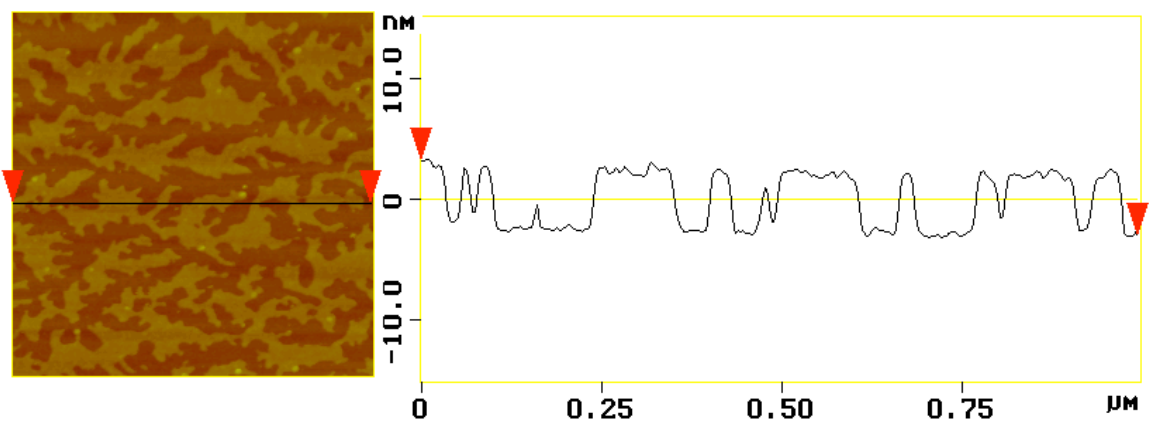

Figure S-4. Height image and section profile (AFM, tapping mode, $1 \times 1 \mu \mathrm{m}$ ) of a monolayer of POM transferred from the surface of a pure water subphase to an OTS modified silicon substrate. 
References:

(1) Yan, X.; Janout, V.; Hsu, J. T.; Regen, S. L J. Am. Chem. Soc., 2003, 125, 80948095 (2003).

(2) Markowitz, M.A.; Janout, V.; Castner, D.G.; Regen, S.L. J. Am. Chem. Soc., 1989, 111, 8192-8200. 